\title{
Motives of Arabic Speaking Viewers for Watching English or Dubbed TV Programs
}

\section{Ahmed Ankit*}

External Relations \& Cultural Affairs, Ajman University of Science and Technology, UAE

\begin{abstract}
This research studies the motives that lead Arabic-speaking university students to watch television programs in English or dubbed in Arabic, and diagnoses the possible effects of these programs on these young people. A field study was conducted on a sample of viewers of the MBC2 and MBC4 Channels in the UAE. A questionnaire was used as a tool to cover a sample of the community comprised of 200 young people who attend various public and private universities in the UAE, aged generally between 18 and 30. The applied study proves that there is no relationship between gender and audience preference, and that there is an independence of respondents' academic specialization and choice of channel. The study's results show that learning English is among the most important motives for the respondents to watch these programs and that $90 \%$ of respondents believe that watching foreign programs has negative effects on university youth.
\end{abstract}

Keywords: Translation; Dubbing; TV programs; Subtitles

\section{Introduction}

One of the most striking features of the recent revolution in communication and information technology is the emergence and global dissemination of satellite transmission. Satellite transmission is divided into different international institutional clusters, each with strategic economic, political, cultural, and social goals and directions. Satellite transmission has become a multi-dimensional investment area. Billions of dollars have been spent on achieving the objectives of the investing states and institutions. Among the results of these developments is the emergence of effective and influential actors. Thus, communities are undergoing enormous change in their reactions. Communities in the Arab world are affected by these developments, as they import communication techniques and undergo their effects with no active role in the audio-visual communication fields at the international level. Thus, there is an abundance of satellite channels that target Arabs, especially young people, who represent almost half of the population of Arab societies. Imported programs are overwhelming to the extent that local programming cannot compete for influence on society. The Middle East Broadcasting Corporation (MBC) is among the channels that have the greatest viewing audience in the Arab world, particularly through their offering of English-language programs and programs dubbed into Arabic. In fact, dubbing has become a very attractive approach to viewers who want to identify with the characters in these programs and find discourse in Arabic more accessible.

\section{Background}

The era of the media and information revolution has had an enormous impact on the thinking trends of young generations. Some phenomena observed among young people, especially university students, include indifference, neglect, and dereliction of duties, poor creativity, lack of initiative and excellence, and a prevalence of behavioral abnormalities. As Guttman [1] maintained, "One of the interesting shifts that the communication devices, digitalized media and the internet have started to bring into our lives, is the possibility for the decentralization of power hierarchy structures within the society".

Arab countries are witnessing changes just like the rest of the world, but they come in different forms, as the communities in the Arab world tend to be conservative and to cling to their distinctive cultural features. TV programs are very influential in those societies, as they constitute a significant source of information and entertainment. As Guttman [1] wrote:

Learning would be exceedingly laborious, not to mention hazardous, if people had to rely solely on the effects of their own actions to inform them what to do. Fortunately, most human behavior is learned observationally through modeling: from observing others one forms an idea of how new behaviors are performed, and on later occasions this coded information serves as a guide for action [2].

\section{Research importance}

This research examined the motives that lead university students in the United Arab Emirates (UAE) to watch English programs and to diagnose the effects of these programs. The significance of this study lies in the fact that recorded media is the medium through which the masses gain access to information as well as entertainment. The media plays a very important role in everyday life, and television is a widely used tool for mass communication. Students are a conscious part of the nation as well as the main viewers of TV programs, so their opinions about those programs and their effects have a profound significance in society.

\section{Research goals}

(1) To shed light on the inception of the MBC Group and to examine the nature of the $\mathrm{MBC} 2$ and $\mathrm{MBC} 4$ programs that they broadcast for young people;

(2) To diagnose the issue of students watching foreign programs,

*Corresponding author: Ahmed Ankit, Associate Professor, External Relations \& Cultural Affairs, Ajman University of Science and Technology, UAE, Tel: +97167055550; Fax: +9716-7483866; E-mail: ankit@ajman.ac.ae

Received October 22, 2013; Accepted January 21, 2014; Published January 28,2014

Citation: Ankit A (2014) Motives of Arabic Speaking Viewers for Watching English or Dubbed TV Programs. J Mass Communicat Journalism 4: 174. doi:10.4172/21657912.1000174

Copyright: (c) 2014 Ankit A. This is an open-access article distributed under the terms of the Creative Commons Attribution License, which permits unrestricted use, distribution, and reproduction in any medium, provided the original author and source are credited. 
whether in English or dubbed;

(3) To examine the views of researchers on the possible effects of TV programs on young people;

(4) To study why university students prefer to watch foreign programs on the MBC4 and MBC2 channels.

\section{Assumptions}

The research is built around the following assumptions:

(1) The broadcasting of foreign programs in the UAE has both advantages and disadvantages. The extent to which it is possible to take advantage of the advantages and avoid the disadvantages depends on the nature of education, level of consciousness, and culture of the audience;

(2) University students in the UAE like to watch Western programs on MBC4 and MBC2 channels;

(3) The growing tendency for young people in the UAE to watch foreign programs represents a social and cultural phenomenon worthy of study and analysis;

(4) Emirati university students tend to watch Western programs produced in the source language, English, or dubbed into Arabic.

\section{Research limitations}

Our research analysis has the following limitations:

(1) Number of viewers: we only surveyed university students;

(2) Time: the research took place within the academic year 20112012;

(3) Geography: the subjects were students at public and private universities in the UAE.

\section{Methodology}

This research is descriptive by nature, as it describes the MBC Group viewing community and diagnoses a phenomenon that has emerged with the advent of advanced technology that allows viewers to view programs either in their original language or dubbed into Arabic. With this in mind, the study uses the following methods:

(1) Descriptive methodology is used to characterize the research community and study phenomena related to the research subject, in order to diagnose the issue accurately and identify its methodological and theoretical framework;

(2) Analytical method is used to analyze data related to the field of study and to draw conclusions that meet the objectives of the research.

\section{Research tool}

A questionnaire was chosen as the most suitable tool for this type of descriptive research and was used to cover a sample from the target community.

\section{MBC group}

MBC started airing programs from London on September 18, 1991 through the first Arabic-language channel owned by the private sector, broadcasting in Arabic via satellite. MBC is owned by ARA Group International, which owns United Press News Agency, Spectrum Radio (which broadcasts its programs in Arabic from London), MBC FM Radio (which is broadcast throughout the Arabian Peninsula), and ARA TV Cable Company. The ARA Group emerged as a Saudi center specializing in television production. It should be noted that the ARA Group entered into an agreement in London with the US United International Holding Company, specializing in cable distribution around the world, to provide cable services throughout the Arab region.

MBC Group has attracted a large number of viewers in the Arab world, owing to its being a pioneer in broadcasting, its expertise, and its contracts with leading Arab and foreign media production companies. It focuses on emotional and excitement factors in addressing young Arab and Muslim people, satisfying young men's and women's desire for Western entertainment regardless of the conservatism of the Arab community. The financial and political support enjoyed by $\mathrm{MBC}$ has led to its popularity among Arab viewers. Its drama and talk shows are very popular among young Arab viewers

The network includes nine TV channels: MBC1, MBC2, MBC3, MBC4, MBC Max, MBC Drama, MBC Persia, MBC Action, and AlArabya, in addition to two radio stations: MBC FM, which plays Gulf music, and Panorama FM, which delivers contemporary Arab hit music. It also includes the $\mathrm{O} 3$ Productions Company, which specializes in documentaries, as well as the Middle East News Company (MEN). Several leading websites have emerged from the Group, including www.mbc.net, www.alarabiya.net, and www.alaswaq.net. Despite the difficulty in accurately counting the number of viewers of MBC's channels, some sources estimate the number of Arab viewers attracted by these channels at nearly 50,000, most of them Saudis.

MBC1 began broadcasting on September 18, 1991, after the end of the first Gulf War. It is the only MBC Channel that broadcasts in Arabic, showing movies, series, and programs with Arab artists and actors. In 1994, MBC FM was launched, offering Arab and Gulf music. In 2002, the headquarters of MBC moved from London to Dubai Media City. The group extended its activities and inaugurated new stations specializing in various areas. In 2003, MBC2 was launched, specializing in foreign films, especially those from the United States. This channel is one of the best-known free channels specializing in these programs. On March 3, 2003, the satellite channel Al Arabiya was created to cover the war in Iraq. Al Arabiya is a news channel that broadcasts bulletins around the clock in addition to presenting analytical programs, interviews with senior political and non-political figures, and documentaries. Al Arabiya was set up to compete with the Al Jazeera satellite news channel in attracting Arab listeners and viewers.

In 2004, MBC3 began broadcasting, specializing in children's programs and cartoons. This channel was launched when the group realized that $40 \%$ of its viewers were less than 15 years of age. The channel was started in order to target the new generation of young viewers; among its most popular programs are Yu-Gi-Oh!, Ninja Turtles, Looney Tunes, Batman and Astro Boy. In 2005, MBC Group launched MBC4, which delivers foreign TV programs and series, especially those that originate in the US. It broadcasts in English, and sometimes offers programs translated into Arabic. This channel offers well-known entertainment programs such as Oprah and Dr. Phil, other series including Pepper Dennis, Medium, and ER, as well as many sitcoms, of which the best known is Friends. It also offers exclusive news programs transmitted on $\mathrm{ABC}$ and CBS, such as Good Morning America, 60 Minutes, Jeopardy, Wheel of Fortune, The Insider, and Inside Edition, as well as film and music award ceremonies. Also in 2005, the Panorama FM radio station was launched, targeting young people across the Arab world. This channel broadcasts talk shows and Arab hit music. On March 5, 2007, MBC Group inaugurated MBC 
Action, which specializes in foreign series, thrillers, and adventure movies.

\section{Screen translation}

"Dubbing" is the replacement of one soundtrack by a new one in a different language than the original. "Subtitling" occurs when text is shown together with visual material, such as a film, and usually consists of a written version of the dialogue found in the soundtrack. The subtitle language can either be the same as that of the soundtrack, or a different one. Subtitling of the kind occurring in the films used in this study usually consists of white text on a black background in two rows near the bottom of the picture, appearing at approximately the same time the corresponding lines are heard on the soundtrack. The purpose of dubbing and subtitling is usually to make audio-visual material available for a broader audience. They are based on the translation of the original language text into a new one. The extent of usage differs between different countries and, to some extent, also depends on the target groups. In some countries, the use of dubbing is almost total, while in other countries subtitling is the main choice.

In this paper, we have chosen to focus on dubbing programs only, as there is now a new technology that allows the viewer to select either the original language or the dubbed language. In this case, it is a choice between English as the original language or Arabic as the dubbed language.

Satellite channels have provided opportunities for various segments of youth populations on an international scale. The number of programs that address young people and play a part in developing their emotional and mental lives has increased significantly in recent years. Such exposure has had an enormous impact on the way people behave. We have witnessed that the effect of information without borders has changed the way people behave in the Arab world, which until the 1990s was confined to information provided by one sourcethe government. These influences are even more significant when we take into account the fact that young people aged 15-24 years represent one-fifth of the total population of the Arab world. According to the United Nations Development Program (UNDP), in 2010, 54\% of the population of the Arab region was under 25; this figure was comprised of 121 million children and 71 million young adults, totaling 192 million young people.

The Arab States Broadcasting Union estimated in its 2010/2011 report that there were 722 TV channels serving the Arab region. Despite intensive coverage of the Arab region by satellite TV, other studies suggest that this coverage came too late due to fear, on the part of the media, of its cultural consequences in Arab societies. There are still governments in the Arab world that prefer to maintain a monopoly on television broadcasting. There has also been a strong demand for direct satellite broadcasting. The results of studies conducted in some Arab countries show that since the early 1990s, the audience of foreign channels is increasing at the expense of Arab local channels [3]. In addition, these studies confirm the interaction of Arab viewers with foreign programs on Arab and foreign channels more than with local programs. They show that audience ratings of MBC channels are higher than those of other channels in areas where there is a tendency to watch foreign satellite TV channels such as BBC and Orbit. This is the case for half of the respondents in a sample that was selected randomly from the UAE, Jordan, Kuwait, Tunisia, and Algeria [4].

There are many reasons why Arab university youth watch foreign programs, especially English, French, and other foreign-language programs that have been dubbed into Arabic. Some of these reasons can be inferred from the quality of the programs, which reflect a reality with which young students who have been to English-language schools identify themselves. Others have been demonstrated by media research and studies concerning mass media audiences. Some of these studies indicate that the driving reasons to watch foreign programs are as follows [4]:

(1) Weakness of local Arab programs;

(2) Desire to have access to worldwide renowned programs, such as Oprah, Dr. Oz, and news stations such as CNN and BBC;

(3) Desire to gain knowledge, as Western programs are produced in a more professional way;

(4) MBC's abundance of Western programs, which gives freedom of choice to viewers;

(5) Openness to world cultures in an era of globalization.

\section{Sample and field procedures}

A research community is the geographical, social, professional, and legal framework in which a study takes place. The community surveyed for this study consisted of students in the UAE, which is an Arab federal state located east of the Arabian Peninsula in southwest Asia, bordering the southern shore of the Arabian Gulf. According to the 2009 census, its population amounts to $8,264,070$ inhabitants spread over $83,600 \mathrm{~km}$. The UAE has joint maritime borders to the northwest with Qatar, land and sea borders with Saudi Arabia to the west, and to the southeast with the Sultanate of Oman. The name "Emirates" comes from the seven emirates, which form a union; they are Abu Dhabi, Dubai, Sharjah, Ras Al Khaimah, Ajman, Umm Al Quwain, and Fujairah. There are 107,424 students in more than 73 licensed scientific institutions in the $\mathrm{UAE}$, covering a wide variety of disciplines ranging from medicine and engineering to natural and social sciences. These students thus vary widely in terms of nationality, age, marital status, and social status (The Official Portal of the United Arab Emirates, retrieved from http://www. government.ae/web/guest/higher_studies).It should be noted that this diversity supposes differences in susceptibility to media influence. Despite the multiplicity of public and private characteristics of the research community, we will focus on the properties that we believe represent the variables that directly affect the research results.

The research sample is divided into the following sections;

(1) Sample type. The research sample is a class sample, representing the class of university students: young men and women who attend various public and private universities in the UAE aged generally between 18 and 30 .

(2) Sample size. The size of the class-based sample is determined by calculating the percentage of the number of UAE university students compared to the size of the overall society. The resultof this calculation is 189 , which figure was rounded up to 200 respondents with different general characteristics for exactness of representation and accuracy of results.

(3) Sampling method. Five universities were selected randomly: University of Abu Dhabi, University of Aljazeera, University of Sharjah, UAE University, and University of Ajman. Forty respondents were selected from each university.

(4) Characteristics of the research sample. Table 1 shows the general characteristics of the respondents. 
Citation: Ankit A (2014) Motives of Arabic Speaking Viewers for Watching English or Dubbed TV Programs. J Mass Communicat Journalism 4: 174 doi:10.4172/2165-7912.1000174

Page 4 of 7

\begin{tabular}{|c|c|c|c|c|c|c|c|c|c|c|c|}
\hline Gender & Number & Rate (\%) & Citizenship & Number & Rate (\%) & $\begin{array}{l}\text { Marital } \\
\text { status }\end{array}$ & Number & Rate (\%) & Specialization & Number & Rate (\%) \\
\hline Men & 116 & 58 & National & 124 & 62 & Single & 126 & 63 & Humanities & 86 & 43 \\
\hline Women & 84 & 42 & Arab Expatriate & 70 & 35 & Married & 50 & 25 & Medicine & 30 & 15 \\
\hline- & - & - & Muslim Expatriate & 02 & 1 & Divorced & 16 & 8 & Engineering Sciences & 56 & 28 \\
\hline- & - & - & Foreign Expatriate & 04 & 2 & Widowed & 08 & 4 & Natural Sciences & 28 & 14 \\
\hline Overall & 200 & 100 & - & 200 & 100 & - & 200 & 100 & - & 200 & 100 \\
\hline
\end{tabular}

Table 1: General Characteristics of the Sample.

\begin{tabular}{|l|l|c|c|c|c|c|c|}
\hline $\begin{array}{l}\text { Preferred } \\
\text { programs }\end{array}$ & Gender & \multicolumn{2}{|c|}{ Arab programs } & \multicolumn{2}{|c|}{$\begin{array}{c}\text { Foreign } \\
\text { programs }\end{array}$} & \multicolumn{2}{c|}{ Overall } \\
\hline 1 & Men & 58 & 29 & 56 & 28 & 114 & 57 \\
\hline 2 & Women & 46 & 23 & 40 & 20 & 86 & 43 \\
\hline & Overall & 104 & 52 & 96 & 48 & 200 & 100 \\
\hline
\end{tabular}

Notes: Chi-Sq. $=0.134, \mathrm{DF}=2, \mathrm{P}$-value $=0.935$.

Table 2: Type of Programs Favored by Respondents According to Gender: Arabic vs. Foreign.

\begin{tabular}{|l|l|c|c|c|c|c|c|}
\hline & $\begin{array}{l}\text { Preferred } \\
\text { programs }\end{array}$ & \multicolumn{3}{|l|}{ English programs } & Dubbed programs & \multicolumn{2}{c|}{ Overall } \\
\hline & Gender & Number & Rate (\%) & Number & Rate (\%) & Number & Rate (\%) \\
\hline 1 & Men & 24 & 63.15 & 22 & 37.93 & 46 & 47.91 \\
\hline 2 & Women & 14 & 36.84 & 36 & 62.06 & 52 & 52.08 \\
\hline & Overall & 38 & 39.58 & 58 & 60.41 & 96 & 100 \\
\hline
\end{tabular}

Notes: Chi-Sq. $=5.878, \mathrm{DF}=2, \mathrm{P}$-value $=0.053$.

Table 3: Type of Programs Favored by Respondents According to Gender: English vs. Dubbed.

\begin{tabular}{|l|c|c|c|c|c|c|}
\hline $\begin{array}{l}\text { Preferred } \\
\text { programs }\end{array}$ & \multicolumn{2}{|l|}{ English programs } & Dubbed programs & \multicolumn{2}{c|}{ Overall } \\
\hline Specialization & Number & Rate (\%) & Number & Rate (\%) & Number & Rate (\%) \\
\hline Social Sciences & 16 & 34.78 & 30 & 60 & 46 & 47.91 \\
\hline Medicine & 12 & 26.08 & 04 & 8 & 16 & 16.66 \\
\hline Engineering & 14 & 30.43 & 10 & 20 & 24 & 25 \\
\hline $\begin{array}{l}\text { Natural } \\
\text { Sciences }\end{array}$ & 04 & 8.69 & 06 & 12 & 10 & 10.41 \\
\hline Overall & 46 & 47.91 & 50 & 52.08 & 96 & 100 \\
\hline
\end{tabular}

Notes: Chi-Sq. $=9.177, \mathrm{DF}=6, \mathrm{P}$-value=0.164.

Table 4: Programs Favored by Respondents According to Subject Specialization.

\begin{tabular}{|l|c|c|c|c|c|c|c|c|}
\hline $\begin{array}{l}\text { Preferred } \\
\text { channel }\end{array}$ & \multicolumn{2}{|c|}{ MBC2 } & \multicolumn{2}{c|}{ MBC4 } & \multicolumn{2}{c|}{ Other channels } & \multicolumn{2}{c|}{ Overall } \\
\hline Gender & Number & $\begin{array}{c}\text { Rate } \\
(\%)\end{array}$ & Number & $\begin{array}{c}\text { Rate } \\
(\%)\end{array}$ & Number & $\begin{array}{c}\text { Rate } \\
(\%)\end{array}$ & Number & $\begin{array}{c}\text { Rate } \\
(\%)\end{array}$ \\
\hline 1 & Men & 46 & 57.5 & 14 & 31.81 & 52 & 68.42 & 112 \\
\hline 2 & Women & 34 & 42.5 & 30 & 68.18 & 24 & 31.57 & 88 \\
\hline & Overall & 90 & 40 & 44 & 22 & 76 & 38 & 200 \\
\hline
\end{tabular}

Notes: Chi-Sq. $=15.274, \mathrm{DF}=3, \mathrm{P}$-value $=0.002$.

Table 5: Channel Preference According to Gender.

The field procedures included the following steps:

(1) After establishing the research plan, the researchers designed the initial questionnaire. This was assessed in terms of validity and reliability and then became the questionnaire that was used in the study;

(2) To implement the questionnaire, a team of research assistants trained in filling out the questionnaire form helped respondents to fill it out;

(3) The questionnaires were then collected, numbered, and organized. Afterwards, the two researchers proceeded to extract, schedule, and statistically process the data. They analyzed it and drew conclusions according to the objectives and assumptions of the research.

\section{Questionnaire design}

The initial questionnaire form consisted of 15 paragraphs that dealt with the characteristics of respondents and 11 paragraphs that covered the research's objectives and assumptions. The virtual honesty of the research questionnaire, which consisted of 15 paragraphs, was tested by subjecting it to arbitration: It was brought to the attention of 10 arbitrators with expertise in media research. The questionnaire achieved a virtual honesty rate of $85 \%$, which is high, and was found reliable for obtaining scientific results with a high degree of trust and credibility. One paragraph was modified and two paragraphs were deleted to obtain the final questionnaire, which comprised 13 paragraphs. A re-testing method was applied to demonstrate the stability of the respondents in their answers. The research form was given to an initial sample of 10 respondents. Three weeks later, retesting was conducted on the same sample, showing a 75\% match with the respondents' original answers a reliable proportion for generalizing the questionnaire to the final sample.

\section{Results}

Table 2 shows the Arabic and foreign TV viewing preferences of respondents according to gender at a significance level of 0.05 , a degree of freedom of 2, and a P-value of 0.935 . These results of a Chi-square test show there is no significance level difference. Moreover, Table 2 indicates that $52 \%$ of respondents watch Arab programs and $48 \%$ watch foreign programs. Men watch more programs than women, though the reason for this may be the higher number of men than women in the sample. While Table 2 compares Arabic programs with Western programs broadcast in English, Table 3 compares respondents' preferences for English and dubbed programs according to gender. Table 3 shows a significance level of 0.05 , a degree of freedom of 2 , and a P-value of 0.053 . The Chi-square test shows that there is a difference in significance level: more women watch programs dubbed into Arabic than men, at a rate of $52.08 \%$ to $47.91 \%$, respectively.

Table 4 shows the impact of the subject specialization of respondents on their preference for watching English-language or dubbed programs: it appears that the academic specialization of respondents has no effect on their viewing preferences.

The results extracted from Table 4 show that of the 96 respondents who watched foreign programs, more watched dubbed programs than English-language programs. The reasons for preferring dubbed programs over English programs are that the majority of viewers are more comfortable listening in the Arabic language even when they know English, and that the quality of dubbing has improved immensely in recent decades. The Syrian Arabic dialect, which has gained popularity over the Egyptian dialect, is used in most dubbed programs shown on MBC channels. Rarely are the Arabian Gulf dialect or the Modern Standard Arabic used.

Table 5 shows the channels favored by respondents according to gender. It appears that there are no statistically significance differences, 
Citation: Ankit A (2014) Motives of Arabic Speaking Viewers for Watching English or Dubbed TV Programs. J Mass Communicat Journalism 4: 174 doi:10.4172/2165-7912.1000174

Page 5 of 7

\begin{tabular}{|c|c|c|c|c|c|c|c|c|c|}
\hline \multirow{2}{*}{\multicolumn{2}{|c|}{$\begin{array}{l}\text { Preferred channel } \\
\text { Specialization }\end{array}$}} & \multicolumn{2}{|c|}{ MBC2 } & \multicolumn{2}{|c|}{ MBC4 } & \multicolumn{2}{|c|}{ Other channels } & \multicolumn{2}{|c|}{ Overall } \\
\hline & & \multirow{2}{*}{$\begin{array}{c}\text { Number } \\
36\end{array}$} & \multirow{2}{*}{$\begin{array}{c}\text { Rate }(\%) \\
58.6\end{array}$} & \multirow{2}{*}{$\begin{array}{c}\text { Number } \\
20\end{array}$} & \multirow{2}{*}{$\begin{array}{c}\text { Rate (\%) } \\
58.82\end{array}$} & \multirow{2}{*}{$\begin{array}{c}\text { Number } \\
42\end{array}$} & \multirow{2}{*}{$\begin{array}{c}\text { Rate }(\%) \\
40.38\end{array}$} & \multirow{2}{*}{$\begin{array}{c}\text { Number } \\
98\end{array}$} & \multirow{2}{*}{$\begin{array}{c}\text { Rate }(\%) \\
49\end{array}$} \\
\hline 1 & Social Sciences & & & & & & & & \\
\hline 2 & Medicine & 06 & 9.67 & 02 & 5.88 & 16 & 15.38 & 24 & 12 \\
\hline 3 & Engineering & 12 & 19.35 & 06 & 17.64 & 22 & 21.15 & 40 & 20 \\
\hline \multirow[t]{2}{*}{4} & Natural Sciences & 08 & 12.90 & 06 & 17.64 & 24 & 23.07 & 38 & 19 \\
\hline & Overall & 62 & 31 & 34 & 17 & 104 & 52 & 200 & 100 \\
\hline
\end{tabular}

Notes: Chi-Sq. $=7.948, \mathrm{DF}=12, \mathrm{P}$-value=0.789.

Table 6: Channel Preference According to Subject Specialization.

\begin{tabular}{|c|c|c|c|c|c|c|c|c|c|}
\hline & \multirow{2}{*}{\begin{tabular}{|l|}
$\begin{array}{l}\text { Preferred } \\
\text { channel }\end{array}$ \\
Marital Status \\
\end{tabular}} & \multicolumn{2}{|c|}{ MBC2 } & \multicolumn{2}{|c|}{ MBC4 } & \multicolumn{2}{|c|}{ Other channels } & \multicolumn{2}{|c|}{ Overall } \\
\hline & & Number & Rate (\%) & Number & Rate (\%) & Number & Rate (\%) & Number & Rate (\%) \\
\hline 1 & Single & 36 & 66.66 & 30 & 71.42 & 64 & 61.53 & 130 & 65 \\
\hline 2 & Married & 14 & 25.92 & 10 & 23.80 & 28 & 26.92 & 52 & 26 \\
\hline 3 & Divorced & 02 & 3.70 & 02 & 4.76 & 08 & 7.69 & 12 & 06 \\
\hline \multirow[t]{2}{*}{4} & Widowed & 02 & 3.70 & 0 & 0 & 04 & 3.8 & 06 & 03 \\
\hline & Overall & 54 & 27 & 42 & 21 & 104 & 52 & 200 & 100 \\
\hline
\end{tabular}

Notes: Chi-Sq. $=3.269, \mathrm{DF}=9, \mathrm{P}$-value=0.953.

Table 7: Channel Preference According to Marital Status.

\begin{tabular}{|c|c|c|c|c|c|c|c|c|c|}
\hline & \multirow{2}{*}{$\begin{array}{l}\text { Preferred channel } \\
\text { Nationality }\end{array}$} & \multicolumn{2}{|c|}{ MBC2 } & \multicolumn{2}{|c|}{ MBC4 } & \multicolumn{2}{|c|}{ Other channels } & \multicolumn{2}{|c|}{ Overall } \\
\hline & & Number & Rate (\%) & Number & Rate (\%) & Number & Rate (\%) & Number & Rate (\%) \\
\hline 1 & Nationals & 34 & 56.66 & 22 & 61.11 & 64 & 61.53 & 120 & 60 \\
\hline 2 & Arab Expatriates & 26 & 43.33 & 14 & 38.88 & 34 & 32.69 & 74 & 37 \\
\hline 3 & Muslim Expatriates & 0 & 0 & 0 & 0 & 04 & 3.84 & 04 & 3.84 \\
\hline \multirow[t]{2}{*}{4} & Other Expatriates & 0 & 0 & 0 & 0 & 02 & 1.92 & 02 & 1.92 \\
\hline & Overall & 60 & 30 & 36 & 18 & 104 & 52 & 200 & 100 \\
\hline
\end{tabular}

Notes: Chi-Sq. $=6.905, \mathrm{DF}=6, \mathrm{P}$-value $=0.330$.

Table 8: Channel Preference According to Nationality.

\begin{tabular}{|l|l|c|c|c|c|c|c|}
\hline & Viewing regularity & \multicolumn{2}{|c|}{ Regularly } & \multicolumn{2}{c|}{ Occasionally } \\
\hline & Gender & Number & Rate (\%) & Number & Rate (\%) & Number & Rate (\%) \\
\hline 1 & Men & 08 & 40 & 34 & 44.73 & 42 \\
\hline 2 & Women & 12 & 60 & 42 & 55.26 & 54 \\
\hline & Overall & 20 & 20.83 & 76 & 79.16 & 56.25 \\
\hline
\end{tabular}

Notes: Chi-Sq. $=0.144, \mathrm{DF}=2, \mathrm{P}$-value $=0.930$.

Table 9: Viewing Regularity of English-Language and Arabic-Dubbed Programs According to Gender.

which means that a relationship exists between the respondents' sex and the channels they prefer to watch. Table 5 also demonstrates that $40 \%$ of respondents of both sexes watch $\mathrm{MBC} 2$, followed by $38 \%$ who watch other channels. MBC4's audience rate is $22 \%$. Table 6 shows that there is no relationship between the subject specialization of respondents and their viewing preferences. The results in this table demonstrate the independence of respondents' specialization and their choice of channel. Table 6 shows that $49 \%$ of the total number of sample viewers are students who specialize in social sciences. A majority of respondents watch programs on other channels (52\%), while $31 \%$ watch MBC2, and $17 \%$ watch MBC4. Table 6 indicates that there is no relation between the marital status of respondents and the satellite channels that they prefer to watch. Table 7 shows that single people watch TV programs most often $(65 \%)$, followed by married people $(26 \%)$. The reason why singles come out on top is that they represent $63 \%$ of the total sample, are generally younger and do not have as many responsibilities. This table also shows that more than half of the respondents do not view programs on either MBC2 or MBC4. Table 8 shows that nationality is independent from the channels that respondents prefer.

This table shows that UAE nationals watch television more than respondents of other nationalities. One of the reasons for this may simply be their higher proportion in the sample.
The Chi-square test on the data in Table 9 shows that the high order variant is not related to the second variant, that is, there is no difference in terms of gender in respondents' regularity of viewing English and dubbed programs. At the same time, it is worth noting that Table 9 shows that women $(60 \%)$ watch both English and dubbed programs more regularly than men (40\%). Regularity results show that $79.16 \%$ of respondents view English and dubbed programs only now and then, while just $20.83 \%$ view them regularly. Table 10 shows that the first variant is not independent from the second variant that is, watching the channel and motives for watching it. There is no significant difference between respondents' motives and their channel preference. This confirms the existence of a relationship between the positive effects of TV programs and the motives of the respondents in their preference to view $\mathrm{MBC} 2, \mathrm{MBC} 4$, or other channels. Table 10 shows that a desire to improve their English language skills is the most important motive for respondents to watch foreign programs (41\%), followed by entertainment and leisure (20\%), acquisition of skills and experience (14\%), learning about other cultures (12\%), learning new models of behavior (7\%), and other influences (6\%). Table 11 shows that the first variant, desire to learn language, is independent of the second variant, level of education and belief that watching foreign programs helps viewers to learn languages. The results also show that 
Citation: Ankit A (2014) Motives of Arabic Speaking Viewers for Watching English or Dubbed TV Programs. J Mass Communicat Journalism 4: 174 doi:10.4172/2165-7912.1000174

Page 6 of 7

\begin{tabular}{|c|c|c|c|c|c|c|c|c|c|}
\hline & \multirow{2}{*}{\begin{tabular}{|l} 
Preferred channel \\
Audience motives
\end{tabular}} & \multicolumn{2}{|c|}{ MBC2 } & \multicolumn{2}{|c|}{ MBC4 } & \multicolumn{2}{|c|}{ Other channels } & \multicolumn{2}{|c|}{ Overall } \\
\hline & & Number & Rate (\%) & Number & Rate (\%) & Number & Rate (\%) & Number & Rate (\%) \\
\hline 1 & $\begin{array}{l}\text { Acquisition of skills and } \\
\text { experience }\end{array}$ & 12 & 13.33 & 06 & 10.71 & 10 & 18.51 & 28 & 14 \\
\hline 2 & $\begin{array}{l}\text { Learning new behavioral } \\
\text { models }\end{array}$ & 04 & 4.44 & 06 & 10.71 & 04 & 7.40 & 14 & 07 \\
\hline 3 & Learning English & 50 & 55.55 & 24 & 42.85 & 08 & 14.81 & 82 & 41 \\
\hline 4 & Entertainment and leisure & 14 & 15.55 & 12 & 21.42 & 14 & 25.92 & 40 & 20 \\
\hline 5 & Access to other cultures & 06 & 6.66 & 06 & 10.71 & 12 & 22.22 & 24 & 12 \\
\hline \multirow[t]{2}{*}{6} & Other positive effects & 04 & 4.44 & 02 & 3.57 & 06 & 11.11 & 12 & 06 \\
\hline & Overall & 90 & 45 & 56 & 28 & 54 & 27 & 200 & 100 \\
\hline
\end{tabular}

Notes: Chi-Sq. $=29.004, \mathrm{DF}=15, \mathrm{P}$-value $=0.016$

Table 10: Motives for Watching English-Language and Dubbed Programs.

\begin{tabular}{|c|c|c|c|c|c|c|c|c|c|}
\hline & \multirow[b]{2}{*}{ Specialization } & \multicolumn{2}{|c|}{$\begin{array}{l}\text { Help viewers learn } \\
\text { foreign languages }\end{array}$} & \multicolumn{2}{|c|}{$\begin{array}{l}\text { Help viewers develop } \\
\text { foreign language skills }\end{array}$} & \multicolumn{2}{|c|}{$\begin{array}{l}\text { Do not help with } \\
\text { languages }\end{array}$} & \multicolumn{2}{|c|}{ Overall } \\
\hline & & Number & Rate (\%) & Number & Rate (\%) & Number & Rate (\%) & Number & Rate (\%) \\
\hline 1 & Social Sciences & 24 & 52.17 & 36 & 45.00 & 40 & 54.05 & 100 & 50 \\
\hline 2 & Medicine & 04 & 8.69 & 12 & 15.00 & 08 & 10.81 & 24 & 12 \\
\hline 3 & Engineering & 10 & 21.73 & 22 & 27.5 & 18 & 24.32 & 50 & 25 \\
\hline 4 & Natural Sciences & 08 & 17.39 & 10 & 12.5 & 08 & 10.81 & 26 & 13 \\
\hline Overall & Overall & 46 & 23 & 80 & 40 & 74 & 37 & 200 & 100 \\
\hline
\end{tabular}

Notes: Chi-Sq. $=3.172, \mathrm{DF}=9, \mathrm{P}$-value=0.957.

Table 11: Respondents' Beliefs about the Importance of Foreign-Language Programs.

\begin{tabular}{|c|c|c|c|c|c|c|c|}
\hline & & \multicolumn{2}{|c|}{ Help globalize viewers' culture } & \multicolumn{2}{|c|}{ Do not help with globalization } & \multicolumn{2}{|c|}{ Overall } \\
\hline & Specialization & Number & Rate (\%) & Number & Rate $(\%)$ & Number & Rate (\%) \\
\hline 1 & Social Sciences & 62 & 52.54 & 40 & 48.78 & 102 & 51 \\
\hline 2 & Medicine & 10 & 8.47 & 14 & 17.07 & 24 & 12 \\
\hline 3 & Engineering & 32 & 27.11 & 12 & 14.63 & 44 & 22 \\
\hline 4 & Natural Sciences & 14 & 11.86 & 16 & 19.51 & 30 & 15 \\
\hline & Overall & 118 & 59 & 82 & 41 & 200 & 100 \\
\hline
\end{tabular}

Notes: Chi-Sq. $=8.429, \mathrm{DF}=6, \mathrm{P}$-value $=0.208$.

Table 12: Respondents' Beliefs about the Role of Foreign Programs in Viewers' Cultural Globalization.

\begin{tabular}{|c|c|c|c|c|c|c|c|c|c|c|c|c|c|c|c|}
\hline & \multirow[b]{2}{*}{ Nationality } & \multirow{2}{*}{\begin{tabular}{|c|}
$\begin{array}{c}\text { Behavioral } \\
\text { deviations }\end{array}$ \\
No.
\end{tabular}} & \multicolumn{2}{|c|}{$\begin{array}{l}\text { Behavioral } \\
\text { deviations }\end{array}$} & \multicolumn{2}{|c|}{$\begin{array}{c}\text { Discarding } \\
\text { particularity and } \\
\text { identity }\end{array}$} & \multicolumn{2}{|c|}{$\begin{array}{c}\text { Lower academic } \\
\text { levels }\end{array}$} & \multicolumn{2}{|c|}{ Social problems } & \multicolumn{2}{|c|}{ Other effects } & \multicolumn{2}{|c|}{ No effects } & \multirow{2}{*}{$\begin{array}{l}\text { Overall } \\
\text { Rate (\%) }\end{array}$} \\
\hline & & & Rate(\%) & No. & Rate (\%) & No. & Rate (\%) & No. & Rate (\%) & No. & Rate (\%) & No. & Rate (\%) & No. & \\
\hline 1 & Nationals & 42 & 56.7 & 22 & 61.1 & 06 & 65 & 30 & 68.1 & 14 & 70 & 12 & 66.6 & 126 & 63 \\
\hline 2 & Arab Expatriates & 30 & 40.5 & 14 & 38.8 & 02 & 25 & 10 & 22.7 & 04 & 20 & 06 & 33.3 & 66 & 33 \\
\hline
\end{tabular}

Notes: Chi-Sq. $=2.818, \mathrm{DF}=6, \mathrm{P}$-value $=0.831$.

Table 13: Respondents' Beliefs about the Adverse Effects of Watching Foreign Programs.

$40 \%$ of respondents believe that watching foreign programs helps to develop the viewer's language skills, while $37 \%$ do not think so and $23 \%$ believe that it helps viewers learn foreign languages.

Table 12 shows the existence of statistically significant differences between respondents' belief in the contribution of foreign programs to the globalization of viewers' culture and respondents' educational background, which has no effect on viewers' belief in the potential for globalization. Thus, the first variant, level of education, is independent of the second variant, belief in the potential for cultural globalization. Table12 also shows that there were more respondents who said that watching foreign programs helps with cultural globalization than respondents who said the opposite. Table 13 indicates the presence of significance level differences between the respondents' nationality and the perceived harmful effects of foreign programs. This means that there is a relationship between the respondents' nationality and whether they watch foreign programs.
The same table shows that $37 \%$ of respondents believe that foreign programs cause deviations in behavior among young people; $22 \%$ believe that they lead to social problems; $18 \%$ believe that they affect viewers' identities and their cultural and civilizational particularities; $4 \%$ believe that they lead to lower academic levels for university students; $10 \%$ think that they lead to effects other than those mentioned in the table; and only $9 \%$ do not believe that these programs have any harmful effects on university students.

Table 14 shows that there is no statistically significant difference between the marital status of the respondents and their belief in the adverse effects of foreign programs. However, there is a relationship between these two variants. The results of the Chi-Square test show that the P-value is 0.000 , the degree of freedom 6 , and significance level 0.05 . The Chi-Square value is smaller than the significance level, which emphasizes the relationship of marital status with the harmful effects of foreign programs. 
Citation: Ankit A (2014) Motives of Arabic Speaking Viewers for Watching English or Dubbed TV Programs. J Mass Communicat Journalism 4: 174 doi:10.4172/2165-7912.1000174

Page 7 of 7

\begin{tabular}{|c|c|c|c|c|c|c|c|c|c|c|c|c|c|c|}
\hline & & \multicolumn{2}{|c|}{$\begin{array}{l}\text { Behavioral } \\
\text { Deviations }\end{array}$} & \multicolumn{2}{|c|}{$\begin{array}{l}\text { Discarding Particularity } \\
\text { and Identity }\end{array}$} & \multicolumn{2}{|c|}{$\begin{array}{c}\text { Lower Academic } \\
\text { Levels }\end{array}$} & \multicolumn{2}{|c|}{ Social Problems } & \multicolumn{2}{|c|}{ Other Effects } & \multicolumn{2}{|c|}{ No Effects } & \multirow{2}{*}{$\begin{array}{l}\text { Overall } \\
\text { Number }\end{array}$} \\
\hline & Marital Status & Number & Rate $(\%)$ & Number & Rate (\%) & Number & Rate (\%) & Number & Rate (\%) & Number & Rate (\%) & Number & Rate (\%) & \\
\hline 1 & Single & 50 & 73.5 & 30 & 83.3 & 04 & 66.6 & 18 & 42.8 & 16 & 44.4 & 10 & 83.3 & 128 \\
\hline 2 & Married & 10 & 14.7 & 06 & 16.6 & 02 & 33.3 & 20 & 47.6 & 16 & 44.4 & 02 & 16.6 & 56 \\
\hline 3 & Divorced & 06 & 8.8 & 0 & 0 & 0 & 0 & 02 & 4.7 & 02 & 5.5 & 0 & 0 & 10 \\
\hline \multirow[t]{2}{*}{4} & Widower & 02 & 2.9 & 0 & 0 & 0 & 0 & 02 & 4.7 & 02 & 5.5 & 0 & 0 & 06 \\
\hline & Overall & 68 & 34 & 36 & 18 & 06 & 3 & 42 & 21 & 36 & 18 & 12 & 6 & 200 \\
\hline
\end{tabular}

Notes: Chi-Sq. $=24.610, \mathrm{DF}=6, \mathrm{P}$-value $=0.000$

Table 14: Respondents' Beliefs about Foreign Programs' Harmfulness According to Marital Status.

\begin{tabular}{|c|c|c|c|c|c|c|c|c|c|c|c|c|c|c|}
\hline & & \multicolumn{2}{|c|}{$\begin{array}{l}\text { Behavioral } \\
\text { Deviations }\end{array}$} & \multicolumn{2}{|c|}{$\begin{array}{l}\text { Discarding } \\
\text { Particularity and Identity }\end{array}$} & \multicolumn{2}{|c|}{$\begin{array}{c}\text { Lower Academic } \\
\text { Levels }\end{array}$} & \multicolumn{2}{|c|}{ Social Problems } & \multicolumn{2}{|c|}{ Other Effects } & \multicolumn{2}{|c|}{ No Effects } & \multirow{2}{*}{$\begin{array}{l}\text { Overall } \\
\text { Number }\end{array}$} \\
\hline & Specialization & Number & Rate (\%) & Number & Rate (\%) & Number & Rate (\%) & Number & Rate (\%) & Number & Rate (\%) & Number & Rate (\%) & \\
\hline 1 & Social Sciences & 38 & 61.2 & 18 & 60 & 08 & 36.3 & 24 & 54.5 & 06 & 5.3 & 14 & 87.5 & 108 \\
\hline 2 & Medicine & 08 & 12.9 & 02 & 06 & 06 & 27.2 & 04 & 9.0 & 04 & 15.3 & 0 & 0 & 24 \\
\hline 3 & Engineering sciences & 12 & 19.3 & 06 & 20 & 04 & 18.1 & 08 & 18.1 & 12 & 46.1 & 0 & 0 & 42 \\
\hline \multirow[t]{2}{*}{4} & Natural Sciences & 04 & 6.4 & 04 & 13.3 & 04 & 18.1 & 08 & 18.1 & 04 & 15.3 & 02 & 12.5 & 26 \\
\hline & Overall & 62 & 31 & 30 & 15 & 22 & 11 & 44 & 22 & 26 & 13 & 16 & 8 & 200 \\
\hline
\end{tabular}

Notes: Chi-Sq. $=32.582, \mathrm{DF}=15, \mathrm{P}$-value $=0.005$.

Table 15: Respondents' Beliefs about the Harmful Effects of Foreign Programs According to Subject Specialization.

Table 15 demonstrates that there is no statistical difference between the nature of the perceived harmful effects and the specialization of the viewers. However, there is a relationship between the academic specialization of the respondents and their opinions on the adverse effects of watching foreign programs. This table also shows that $31 \%$ of respondents believe that the foreign English and dubbed programs cause behavioral abnormalities, $22 \%$ believe that these programs cause social problems, $15 \%$ believe they lead to the erosion of national identity and particularities, $11 \%$ think they cause lower scientific level of university students while $13 \%$ believe that they lead to effects other than those mentioned in the questionnaire, while only $8 \%$ do not believe that the viewing of foreign programs has any adverse effects.

\section{Discussion and Conclusions}

This study proves that there is no relationship between gender and audience preferences when it comes to young people's choice of TV programs in the UAE. The results show that more people watch Arabic programs (52\%) than foreign programs (48\%). The results also show little difference between men and women in preferring Englishlanguage or Arabic-dubbed programs: women watch more dubbed programs than men do by a margin of only $52.08 \%$ to $47.91 \%$. The study shows the independence of respondents' specialization and their choice of TV channel. The results also show that students in the social sciences watch more television than other respondents. The study confirms that UAE nationals watch more television than students of other nationalities. Part of the reason for this may be due to their higher proportion in the sample. More respondents prefer MBC2 than MBC4. The results illustrate no relationship between the sex of respondents and their preference for English or dubbed programs. Women were found to more regularly watch both English-language and dubbed programs than men. The results also explain that the motives of respondents in preferring $\mathrm{MBC} 2$ and $\mathrm{MBC} 4$ have a relationship with the positive effects of the programs on these channels. The study's results show that learning English is among the most important motives for the respondents to watch foreign-language programs. Other motives include entertainment and leisure, acquisition of skills and experience, access to other cultures, learning new behavior models, and other influences. More viewers watch MBC2 than either MBC4 or other channels. The results show that many respondents believe that watching foreign programs helps develop viewers' native language skills, while about half of them believe that watching foreign programs helps viewers learn foreign languages. A majority of respondents also believe that watching foreign programs helps in the globalization of the viewers' culture. Yet, over one-third of respondents believe that viewing foreign programs causes deviations of behavior among young people, while others believe that such programs can lead to social problems, changes in the identity of respondents and their cultural and civilization particularities, and lower academic levels for university students. Just one-tenth of respondents do not believe that watching foreign programs has any negative effects on university students.

\section{References}

1. Guttman B (2011) The change of power paradigm in art education: Art education and non violent communication. Faculty of Music and Visual Arts University of Pécs.DLA thesis.

2. Bandura A (2010) Social learning theory. Englewood Cliffs, NJ: Prentice Hall.

3. Lotfi M (1989) Survey on NTC in Algeria. Algerian Journal of Communication INSIC 3: 65

4. Aisani RA (2010) Media globalization and its effects on foreign satellite TV viewers (1st ed.). Jordan: Modern Books World for Publication and Distribution. 